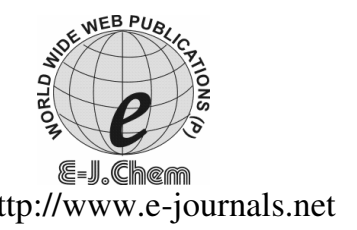

ISSN: 0973-4945; CODEN ECJHAO

E-Journal of Chemistry 2010, 7(1), 222-226

\title{
Synthesis, Characterization and Biological Evaluation of 1, 2-Disubstituted Benzimidazole Derivatives using Mannich Bases
}

\author{
B. ANIL REDDY \\ Department of Pharmaceutical Chemistry, \\ Maheshwara College of Pharmacy, Chitkul, Patancheru-500 072, A.P, India. \\ drbanilreddy@gmail.com
}

Received 16 June 2009; Accepted 10 August 2009

\begin{abstract}
The ring system in which a benzene ring is fused to the 4,5-positions of imidazole is designated as benzimidazole. Condensations of 2-substituted benzimidazole derivatives were synthesized by different carboxylic acids using Mannich base and anti-inflammatory activity. The various positions on the benzimidazole ring are numbered in the manner indicated with the imino function as number one. The formations of the product were conformed by the analytical and spectral data.
\end{abstract}

Keywords: Benzimidazole derivative, Mannich base, Anti-inflammatory activity.

\section{Introduction}

The ring system in which a benzene ring is fused to the 4,5-positions of imidazole is designated as benzimidazole ${ }^{1}$. The various positions on the benzimidazole ring are numbered in the manner indicated with the imino function as number on $e^{2-4}$. The benzimidazoles possessing free imino hydrogen are tautomeric systems. The two possible tautomeric forms of benzimidazole (and of those of its derivatives possessing a plane of symmetry) are identical and a definite assignment of structure is possible ${ }^{5-7}$.

The formations of the product were confirmed by the analytical and spectral data. Antiinflammatory activity of the synthesized compound was confirmed by significant effect over carrageenan induced paw edema.

\section{Experimental}

$o$-Phenylene diamine was condensed with different aromatic carboxylic acids to give 2- substituted benzimidazole ${ }^{1,3,5}$. The procedure for conventional benzimidazole synthesis is depicted below. 


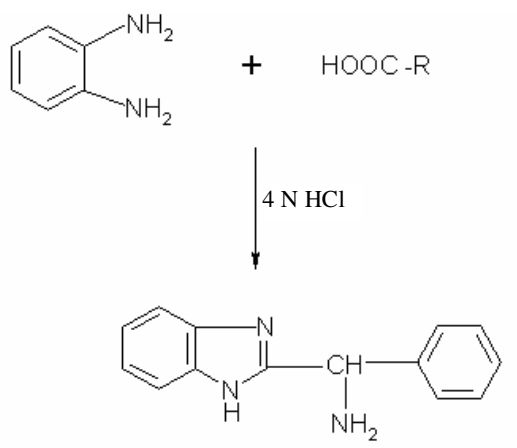

Figure 1. Preparation of benzimidazole derivatives.

Benzimidazole was synthesized by $o$-phenylene diamine $(12 \mathrm{mmol})$ and phenyl glycine (36 mmol) were stirred in $4 \mathrm{~N} \mathrm{HCl}(40 \mathrm{~mL})$ and refluxed for $4 \mathrm{~h}$, then cooled at room temperature. The completion of this reaction was monitored by thin layer chromatography $y^{3,8-10}$. The $\mathrm{pH}$ was adjusted to 7.2 using sodium hydroxide pellets. The resulting brown solid was filtered and washed with water dried in vacuum and recrystallized from acetone.

The yield of 2-(1-amino benzyl) benzimidazole was found to be $78.5 \%$ and the m.p is $280{ }^{\circ} \mathrm{C}$. The completion of the reaction was monitored by thin layer chromatography using solvent system ethyl acetate: $N$-hexane: methanol.

\section{Description}

$\begin{array}{lll}\text { Yield } & = & 78.5 \% \\ \mathrm{~m} . \mathrm{p} & = & 280{ }^{\circ} \mathrm{C} \\ \mathrm{R}_{\mathrm{f}} \text { value } & = & 0.25 \\ \text { Solvent system } & = & \text { Ethylacetate: } N \text {-Hexane: Methanol (3: 2: 1) }\end{array}$

The above mentioned procedure for the synthesis of benzimidazole derivative using conventional various carboxylic acids in presence of conc. $\mathrm{HCl}^{11-13}$, but in present work we have used Mannich bases, which give advantage for various substitutions in benzimidazole nucleus. Benzimidazoles were synthesized by Mannich base by following procedure.

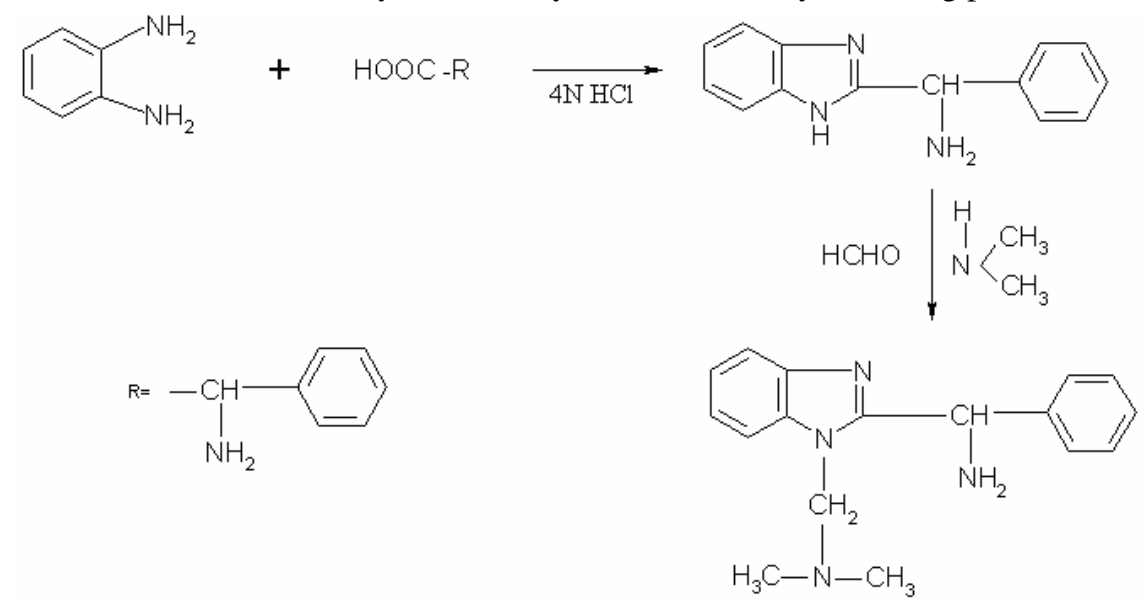

Figure 2. Preparation of benzimidazole using Mannich base. 
The Mannich base used in the above procedure was synthesized by following procedure. 2-(1-Amino benzyl) benzimidazole $(10 \mathrm{mmol})$ was dissolved in dimethyl sulfoxide corresponding to secondary amine $(10 \mathrm{mmol})$ and formaldehyde $(37 \% \mathrm{~W} / \mathrm{V}$ $(15 \mathrm{mmol})$ ). The reactants were refluxed with stirring at $70-75{ }^{\circ} \mathrm{C}$ (The condensation time varied between 5-8.5 h). The completion of this reaction was monitored by thin layer chromatography. The reaction mixture was kept in a refrigerator for overnight; the solvent removed under reduced pressure and the product was recrystallized from acetone.

The yield of 1-dimethyl amino-2-(2-benzyl amine) benzimidazole was found to be $65 \%$ and m.p was found to be $185{ }^{\circ} \mathrm{C}$. The completion of the reaction was monitored by the thin layer chromatography using solvent system ethyl acetate: $N$-hexane: methanol.

\section{Description}

$\begin{array}{lll}\text { Yield } & = & 65 \% \\ \mathrm{~m} . \mathrm{p} & = & 185^{\circ} \mathrm{C} \\ \mathrm{R}_{\mathrm{f}} \text { value } & = & 0.25 \\ \text { Solvent system } & = & \text { Ethyl acetate: } N \text {-Hexane: Methanol (3: } 2: 1)\end{array}$

\section{Results and Discussion}

In the present work, ortho phenylene diamine was condensed with different acids such as phenyl glycine and phenyl acetic acid. The completion of the reaction was confirmed by TLC and was characterized by IR. The melting point of the synthesized compound was measured by open capillary tube method.

IR, ${ }^{1} \mathrm{H}$ NMR and mass spectrum confirmed the chemical structure of the synthesized compound, which is showed in Figure 3-5. In the mass spectrum of the synthesized compound produced $\left(\mathrm{M}^{+}\right)$molecular ion peak such as 223 for compound-I, which corresponds with their molecular weights.

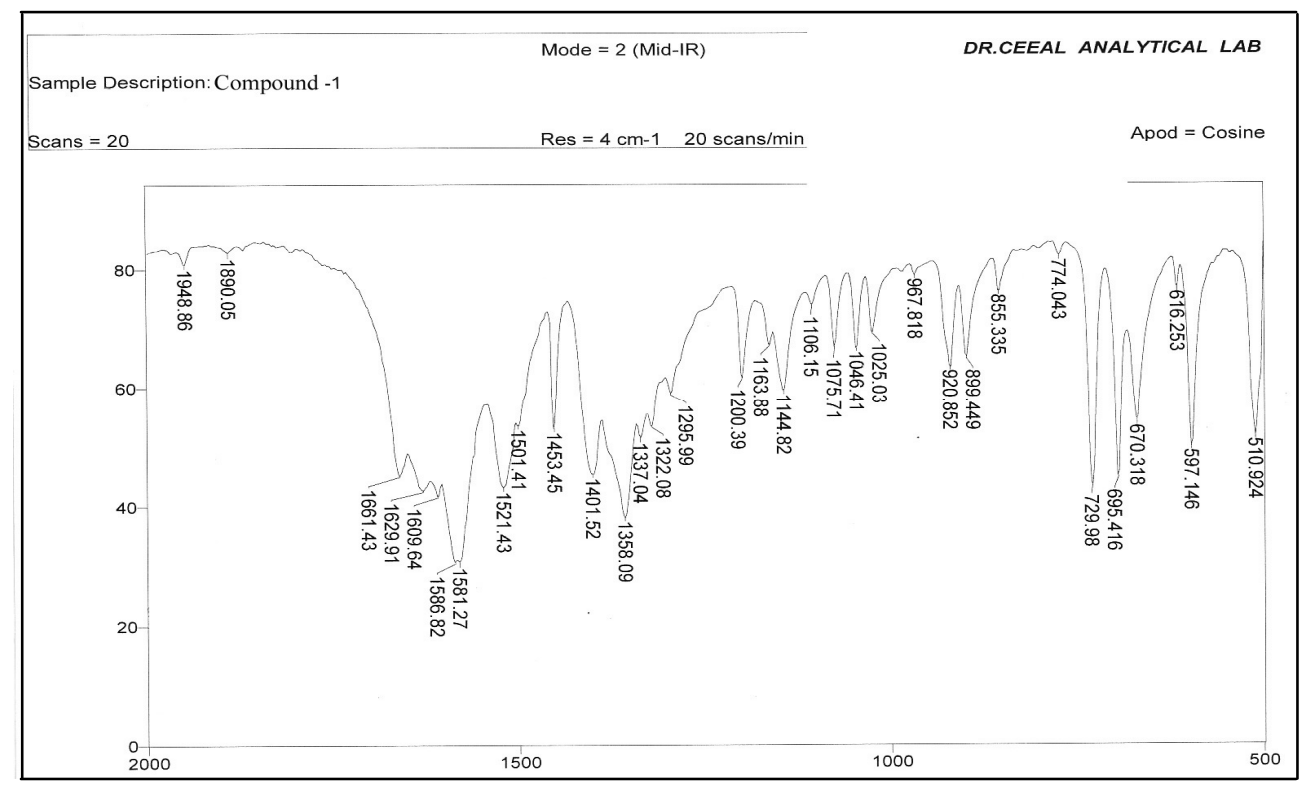

Figure 3. IR spectrum of synthesized compound-I. 


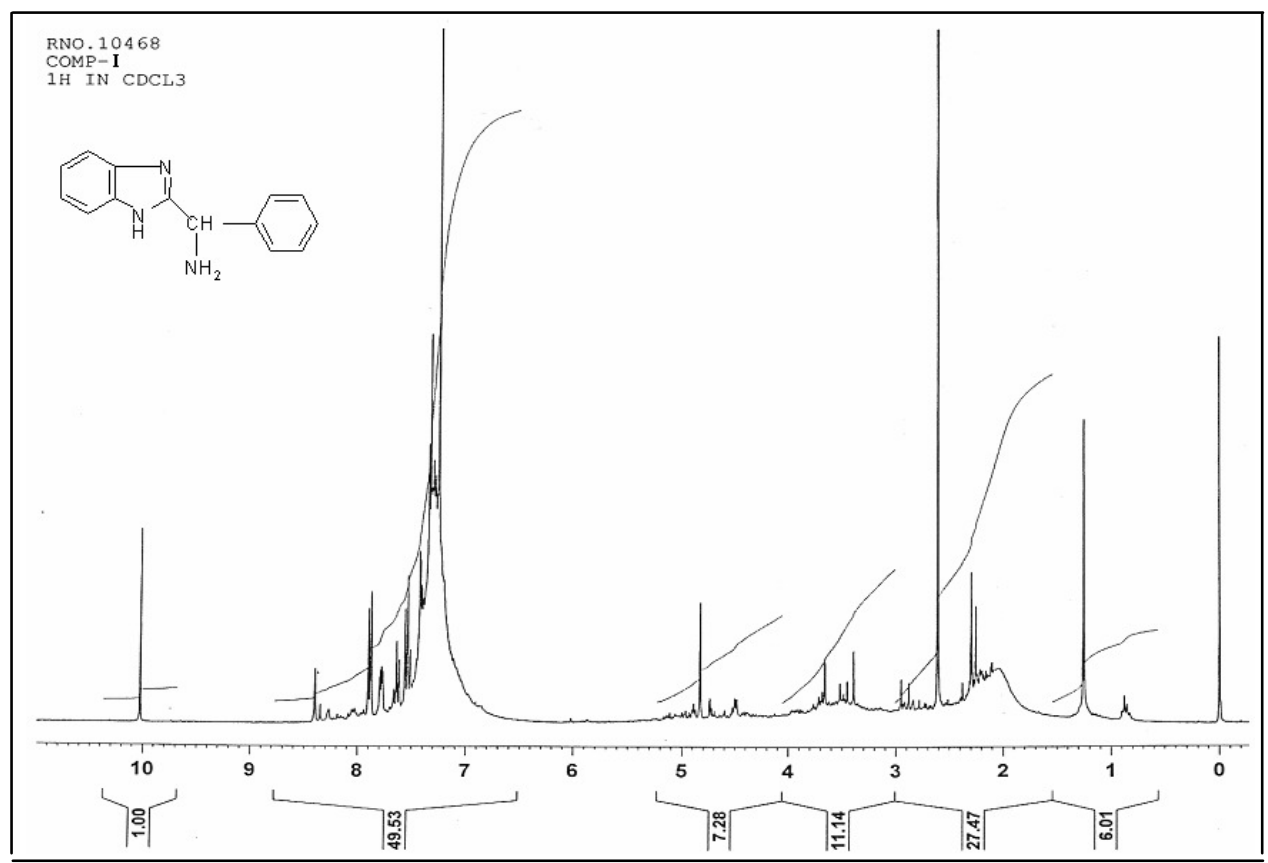

Figure 4. ${ }^{1}$ H NMR Spectrum of synthesized compound-I.

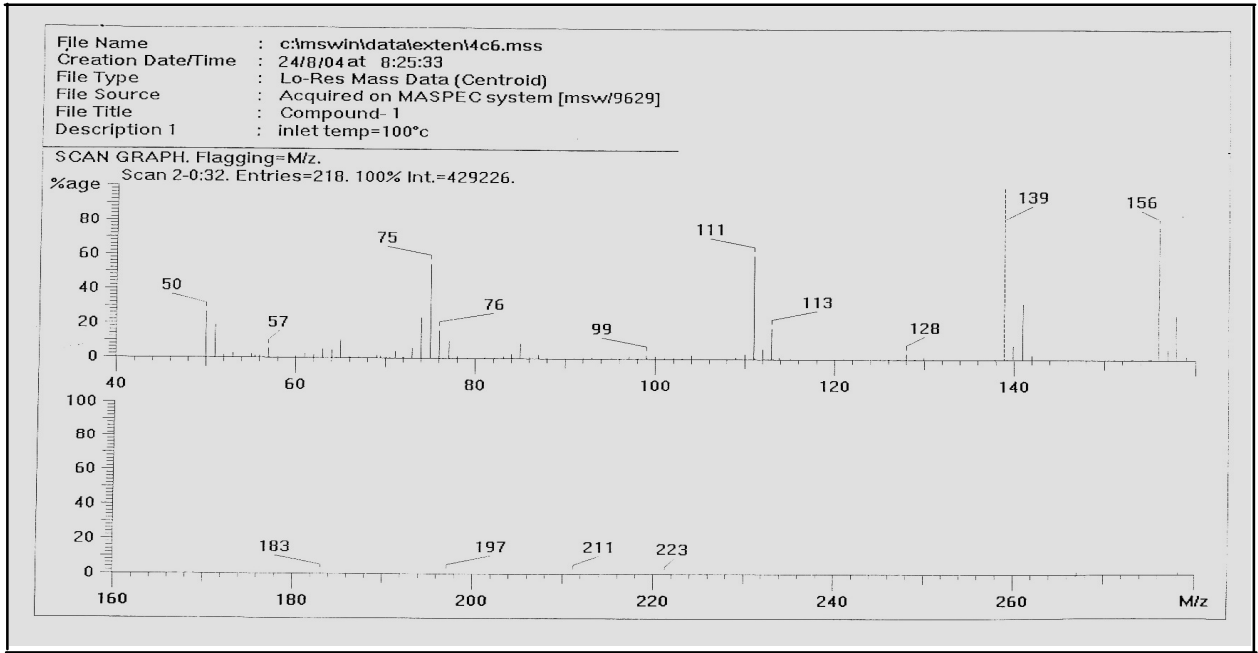

Figure 5. Mass spectrum of synthesized compound-1.

\section{Pharmacological studies}

\section{Acute oral toxicity- acute toxic class method}

Acute oral toxicity studies were performed based on Organization of Economical Cooperation and Development (OECD) guidelines, for the synthesized compound. No toxicity or death was observed for synthesized compound on administration of a dose of $2000 \mathrm{mg} / \mathrm{kg}$. Hence the synthesized compound was considered as safe (x-unclassified). Based on this observation, a dose of $200 \mathrm{mg} / \mathrm{kg}$ was selected for the anti-inflammatory studies. 


\section{Anti-inflammatory studies}

On screening of synthesized compound-I, confirmed significant effect over carrageenan induced paw edema. On percentage protection basis, compound I showed 64\%, while Indomethacin showed $76.15 \%$ when compared to control.

Table 1. Evaluation of anti-inflammatory activity by carrageenan induced hind paw edema in rats.

\begin{tabular}{|c|c|c|c|c|c|}
\hline \multirow{2}{*}{ Compounds } & \multirow{2}{*}{$\begin{array}{c}\text { Dose } \\
\mathrm{mg} / \mathrm{kg}\end{array}$} & \multicolumn{4}{|c|}{ Percentage protection of edema ( Mean \pm SEM ) } \\
\hline & & $2 \mathrm{~h}$ & $3 \mathrm{~h}$ & $4 \mathrm{~h}$ & $5 \mathrm{~h}$ \\
\hline $\begin{array}{l}\text { Synthesized } \\
\text { Compound-I }\end{array}$ & 200 & $5.55 \pm 0.003^{*} 15.38 \pm 0.007^{*}$ & $50.00 \pm 0.005^{*}$ & $60.00 \pm 0.005^{*}$ & $71.42 \pm 0.004^{*}$ \\
\hline $\begin{array}{c}\text { Standard } \\
\text { (Indomethacin) }\end{array}$ & 5 & $5.55 \pm 0.003^{*} 15.38 \pm 0.007^{*}$ & $50.00 \pm 0.005^{*}$ & $66.6 \pm 0.005^{*}$ & $75.00 \pm 0.004^{*}$ \\
\hline
\end{tabular}

All values are mean \pm SEM of 6 animals in each group $* P<0.001$ compared to carrageenan control (100\% edema).

\section{Acknowledgement}

The author is grateful to Dr.A.K. Singh, Professor, Patna, Mr.Sathyapal Gupta, Director, Ranboxy, Mr. VVSS Appalaraju (Malaysia), Mr. Jotish and Mrs.Kundana, Vips Pharma and Mr.Vijay, R\&D Department, IICT for providing necessary facilities during the tenure of this work.

\section{References}

1. Salgaonkar P D and Velingkar V S, Indian drugs, 2000, 37(11), 547- 550.

2. Pandey V K, Khulbe K C, Saxena G, Gupta P and Chendra K, Indian drugs, 1984, 21, 135-138.

3. Sarhan, Hozien and Mahmoud, J Chinese Chem Soc., 2000, 47, 1279-1286 .

4. Raslam M A and Selim M A, J Chinese Chem Soc., 2000, 47, 961- 965.

5. Andi C Dash, Achutananda Acharya and Ranaa K Sahoo, Indian J Chem., 1998, 37A, 759-764.

6. Rashmi Rastogi, Stayavan Sharma and Iyer R N, Indian J Chem., 1979, 18B, 464-467.

7. Syed Abuzar, Satyavan Sharma and Iyer R N, Indian J Chem., 1980, 19B, 599-600.

8. $\quad$ Pritpal Sing and LL Hingorani, Indian J Chem., 1990, 29B, 596-597.

9. Agarwal V K, Stayavan Sharma and Iyer R N, Indian J Chem., 1981, 20B, 398-400.

10. Joel R Huff, Stella W King and Waltred S Saari, J Org Chem., 1982, 47, 582-585.

11. Sukvinder Kaur Chawla, Indian J Chem., 1998, 37A, 904-907.

12. Thakur P, Chekravorthy V and Dash K C, Indian J Chem., 1999, 38B, 1223-1227. 


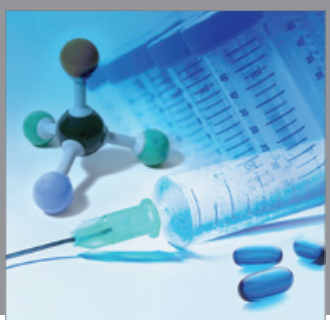

International Journal of

Medicinal Chemistry

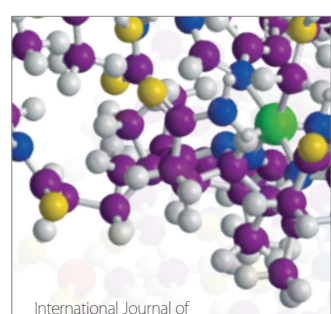

Carbohydrate Chemistry

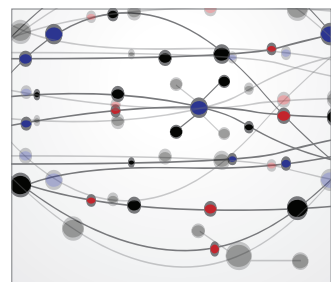

The Scientific World Journal
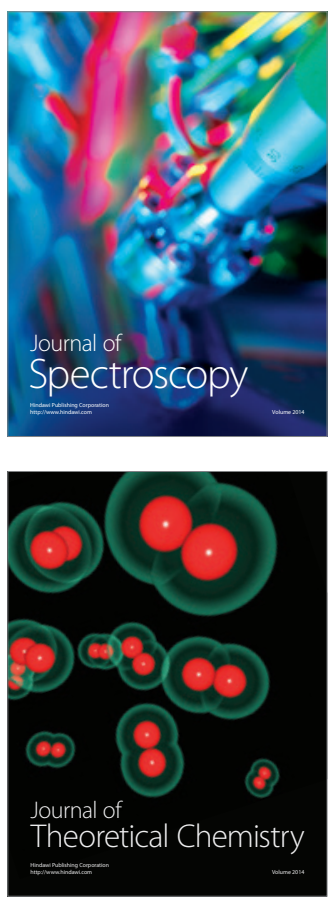
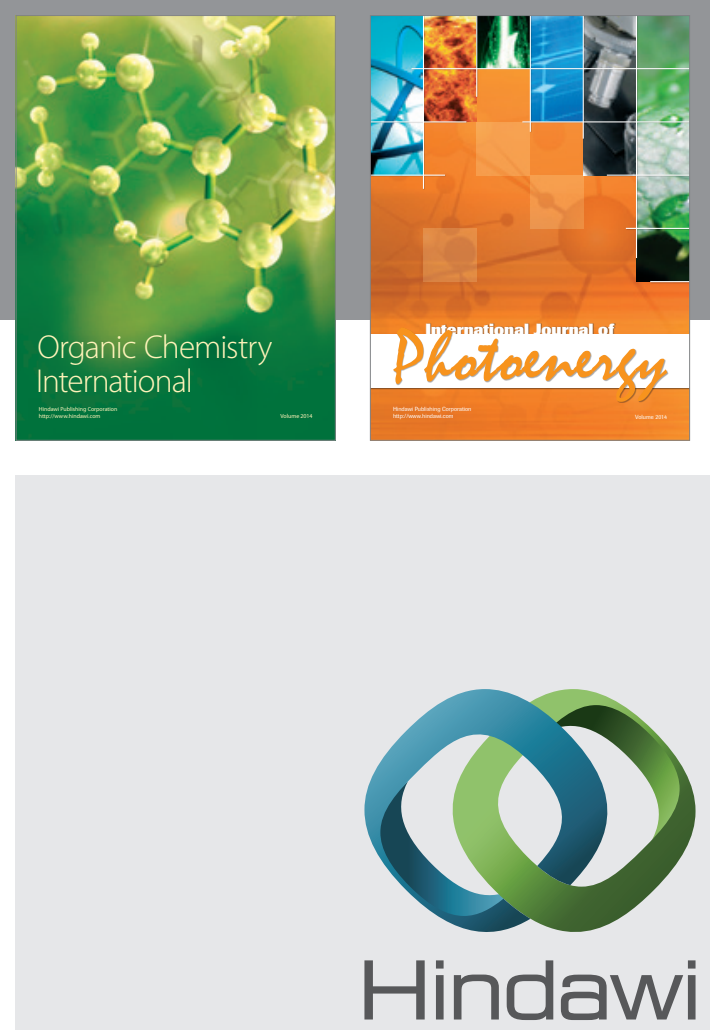

Submit your manuscripts at

http://www.hindawi.com
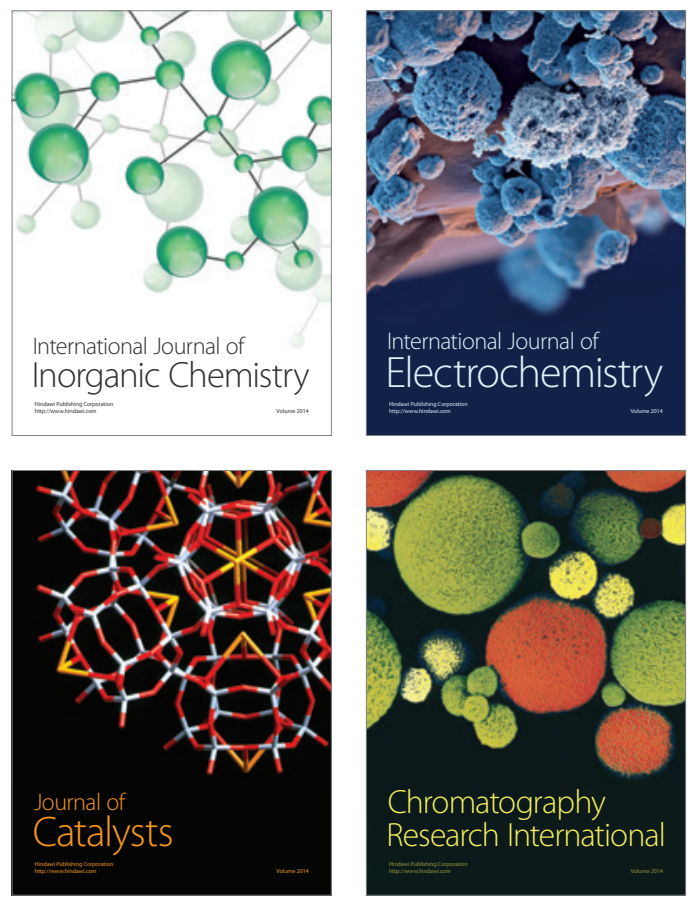
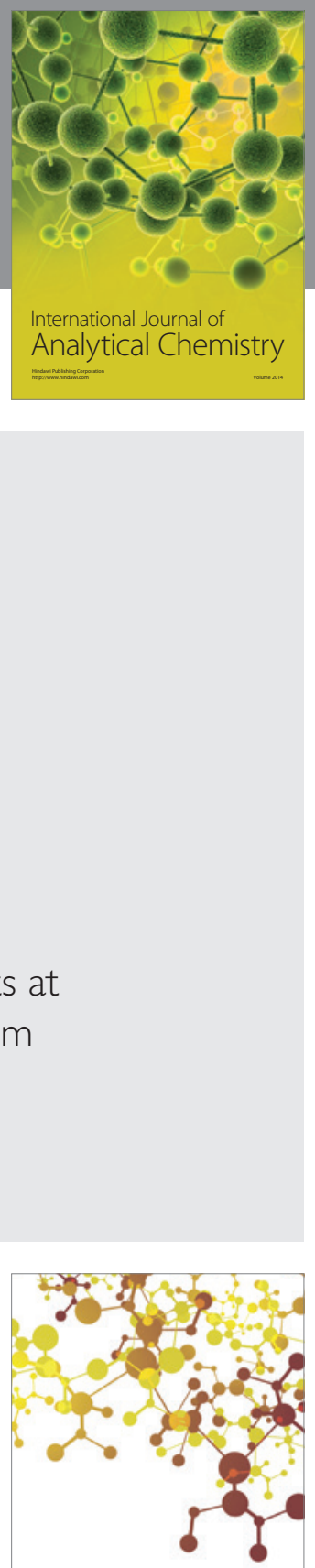

Journal of

Applied Chemistry
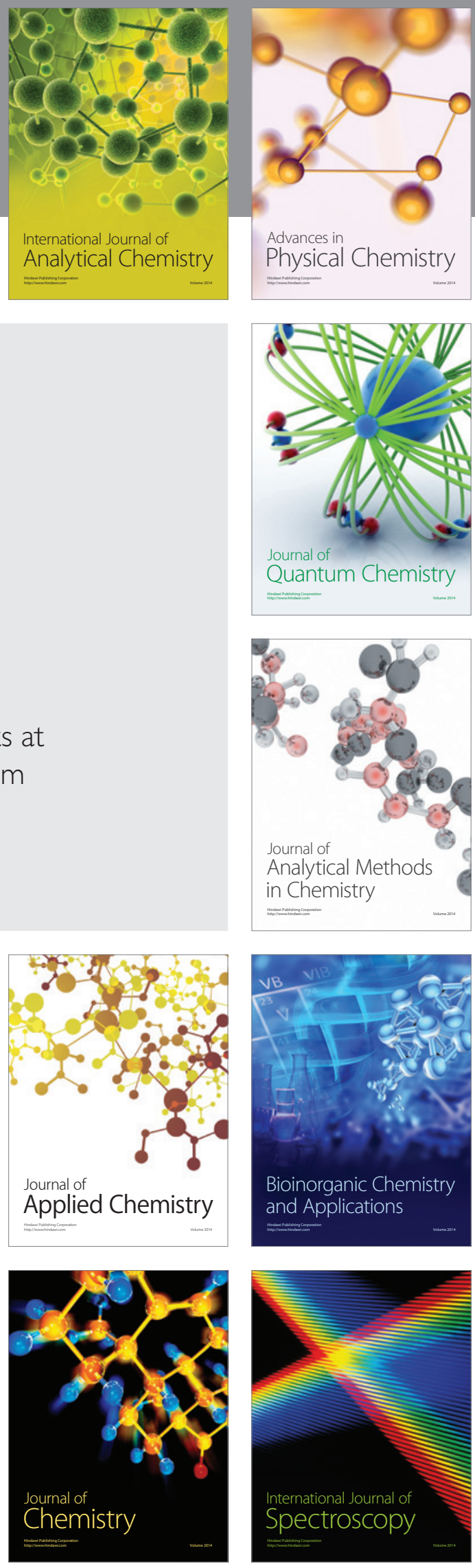